\title{
Healthcare System Accessibility in the Face of Increasing Privatisation in Saudi Arabia: Lessons From Australia
}

\author{
Abdullah Ghthaith Almutairi ${ }^{1} \&$ Hilal Salim Al Shamsi ${ }^{2}$ \\ ${ }^{1}$ Quality Department, Prince Nasser Hospital, Al-Ghat Province, Ministry of Health, Saudi Arabia \\ ${ }^{2}$ Directorate of Planning and Studies, Directorate General of Planning and Studies, Al-Buraimi Governorate, \\ Ministry of Health, Oman \\ Correspondence: Hilal Salim Al Shamsi, Directorate of Planning and Studies, Directorate General of Planning \\ and Studies, Al-Buraimi Governorate, Ministry of Health, Oman.
}

Received: April 27, 2018 Accepted: May 24, 2018 Online Published: June 11, 2018

doi:10.5539/gjhs.v10n7p111 URL: https://doi.org/10.5539/gjhs.v10n7p111

\begin{abstract}
Background: The Kingdom of Saudi Arabia (KSA) is a developing nation with significant resources to improve the nations population health and a planned objective to do so with its Vision 2030 plan. Nonetheless to achieve national strategic goals in health policy and outcomes, the structures and methods necessary to do so must first be elucidated, and outcomes of proposed actions must be appropriately predicted. The primary purpose of this literature review is to compare and critically analyse the structural and policy aspects of the Australian and KSA health systems to offer insights into the potential mechanics of developing further health system accessibility within the KSA. Importantly, this review addresses the issue of accessibility in the context of the recently proposed privatisation of hundreds of services throughout the KSA as a major component of the Vision 2030 plan.
\end{abstract}

Method: 43 peer-reviewed articles were identified using the PRISMA approach and systematically analysed to determine the effects of policy changes in the 2030 Vision to the accessibility of healthcare, in particular the effect of privatisation, as observed in other nations such as Australia.

Findings and Discussion: the literature review demonstrated that privatisation can, but does not always, lead to productivity and efficiency gains, however privatisation also leads to increasing administrative costs and service cost inflation. Health outcomes or service quality indicators are not significantly affected by privatisation. It is probable that privatising health services will reduce accessibility to health services in some subsets of the population.

Conclusion: according to the international evidence, the proposed plan to privatise health services in the KSA will probably have a negative effect on the accessibility of health services and downstream improvement in population health outcomes. If inappropriate governance is not implemented, the plan to privatise services also carries the risk of decreasing access to vulnerable populations and threatens health equity and needs-based health care.

Keywords: privatization or corporatization, access or accessibility, last 10 years

\section{Introduction}

\subsection{Aim}

The aim of this report is to analyse critical components of the healthcare systems in Australia and Saudi Arabia to gather insights and lessons to facilitate improvements to cope with future health demands.

\subsection{Objectives}

1) Contrast the population parameters with healthcare demands for access in Saudi Arabia and Australia.

2) Contrast the accessibility of healthcare services in Australia and the Kingdom of Saudi Arabia.

3) Outline the population of Australia and Saudi Arabia to determine the context and priorities of health service delivery in each country in relation to access.

4) Outline key features of each healthcare system's funding models and structural organisation for accessibility to healthcare.

5) Consider lessons from the Australian system and how these may be applied to the Saudi Arabian 
healthcare system to facilitate improvements to cope with future health demands in relation to access.

\subsection{Rationale and Justification for the Literature Review}

Both Australia and Saudi Arabia are subject to significant population change and unique strain on healthcare budgets. Each system, while unique in the reasons for shifting systematic demands, require appropriate consideration of healthcare spending and organisation in order to continue to support ongoing high quality health service delivery. Australia has a globally recognised high standard of healthcare and health profile to back it up with one of the longest average life expectancy in the world (Van Doorslaer, Clarke, Savage, \& Hall, 2008; World Health Organisation [WHO], 2016a). Additionally, the health system combines both public and private services with relative success, portraying the country as a sound benchmark for privatisation modelling.

Saudi Arabia is a developing nation with a very young population and high birth rate (Ministry of Health [MOH], 2016). The nation is improving its health infrastructure but seemingly lacks the well-appointed systems to manage the changing population health dynamics. The KSA is moving towards a more privatised system and is steadfastly focused on the economics of this plan, as well as the potential for enhanced efficiency, productivity, private investment and economic risk mitigation. Nonetheless, it fails to consider to human downside of privatisation, particularly the impact on accessibility to health services. This systematic review will draw on the experiences in Australian and beyond in order to assess the evidence around the benefits of privatisation in additional to the potential downside of reduced accessibility and therefore equity of health service delivery.

\section{Literature Review}

\subsection{Introduction}

The Kingdom of Saudi Arabia (KSA) is a resource-rich nation with a youthful population. It currently has the opportunity to develop the public health system and enhance private sector investment. The KSA has recently experienced economic pressures and booming population demands. These demands require the identification and implementation of efficiency measures across the entire systems portfolio, including the healthcare budget. The KSA responded to falling oil prices and an increasing demand for important healthcare services by creating the Vision 2030 plan. The plan is ambitiously comprised of numerous health-related changes, including the privatisation of a significant proportion of public health institutions. Vision 2030 is non-transparent regarding how it will achieve its objectives, and is focused mainly on the economic advantages of privatising healthcare services.

This literature review investigates the accessibility of health services in the KSA, comparing KSA healthcare services to more developed health systems in countries like Australia. Taking the intentions and initiatives of the KSA into consideration, the Australian healthcare system is examined as a benchmark to demonstrate the symbiosis of public and private sector service delivery and accessibility. While the KSA and Australia differ culturally, geographically, and economically, this study comparison will draw influential lessons pertaining to healthcare service accessibility and privatisation.

In Australia, healthcare is provided under the national and universal healthcare insurance program, Medicare. This is done through a semi-decentralised funding model. In Saudi Arabia, funding is provided directly to hospitals and health clinics by the Saudi Arabian Ministry of Health (MOH) through a centralised funding model. While both countries provide robust health services, shifting population demands facilitate the need to rethink provisions in order to sustain high quality healthcare services. This paper will examine the contrasting aspects of each system in an attempt to determine the key features of each, as well as establish the potential for systematic improvements in facilitating increased accessibility to health services in the future. In particular, this review evaluates both the KSA and Australian healthcare systems, including their respective demographics, health indicators, and determinants of health; system ownership and funding models (i.e. public, private, and not-for-profit) including methods of financing health and economic balance; organisational aspects of health delivery, education, and training; and the current status of professional workforces. This paper will investigate each of these components through a policy lens, ultimately determining the effects of privatisation on the accessibility of healthcare services in the KSA.

\subsection{Methodology}

This literature review draws upon peer-reviewed articles dated between the years 2007-2017. This has been done by using the PubMed database, as well as through the collection of data from government and creditable healthcare resources such as the World Health Organisation (WHO). The inclusion criteria for this study incorporated only sources published within the past 10 years that have been written in English. This date range was selected on the basis of the recent changes to healthcare organisations within the KSA. This positions the study data so that salient points revolving around the privatisation of healthcare services can be discussed. Two searches were conducted: one for Saudi Arabia and another for Australia. The key words used to locate the appropriate research were: 
"privatisation OR corporatization," "access OR accessibility,"and "last 10 years." "Saudi Arabia" and "Australia" were added to the individual searches in order to locate sources specific to each respective country. The search yielded international perspectives that were utilised as additional supporting evidence regarding the privatisation and accessibility of healthcare services. The search results were evaluated individually to identify their relevancy to this study. Duplicate articles were removed. Relevant articles were found using the references listed within articles found in the initial search. Figure 1 outlines the PRISMA approach, where the search process and yielded articles are demonstrated.
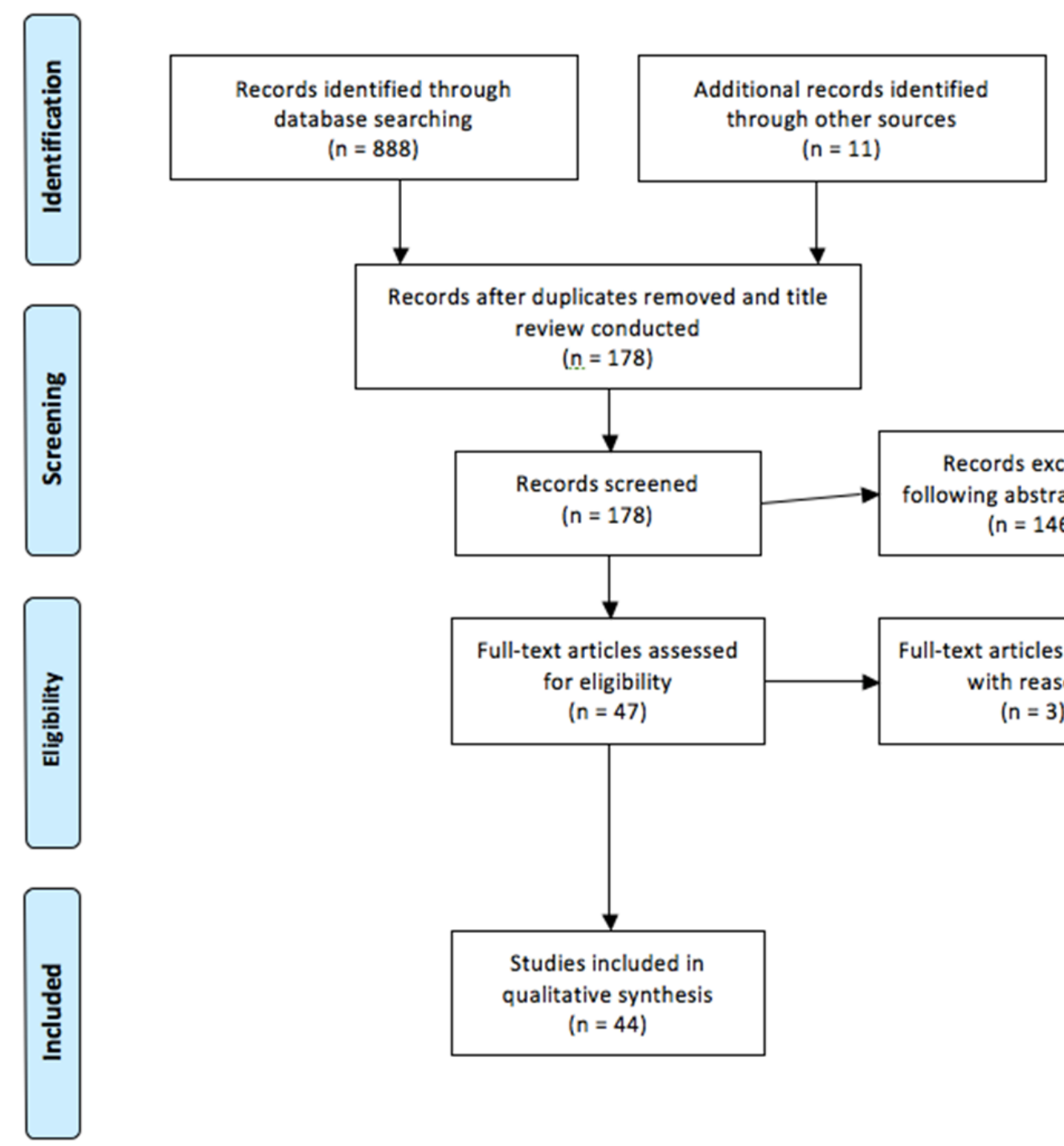

removed and title

view conducted

$(\mathrm{n}=178)$
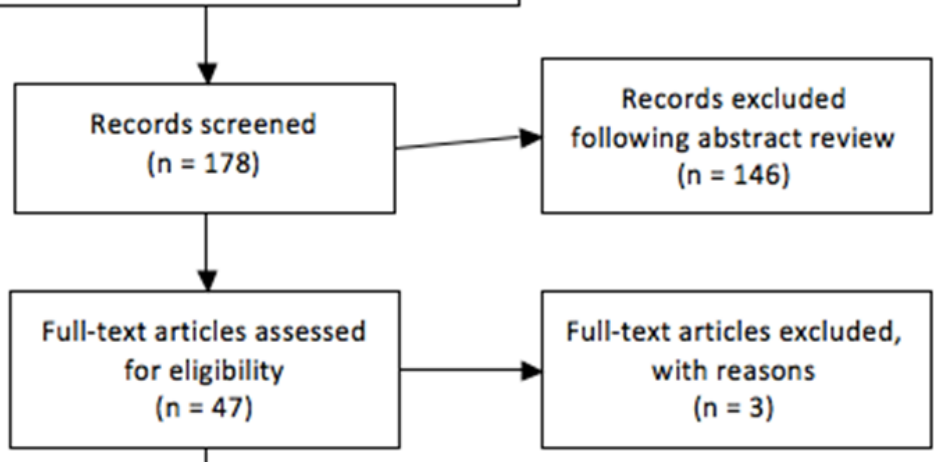

Figure 1. PRISMA approach utilised to determine appropriate articles for review. Adapted from the "Preferred Reporting Items for Systematic Reviews and Meta-Analyses: The PRISMA Statement" by Moher, Liberati,

Tetzlaff, and Altman (2009). PLoS Medicine, 6(7)

The initial search yielded a total of 888 papers, with 11 additional sources being found outside of the initial search. Once duplicate studies had been removed, a total of 178 abstracts were assessed. Of the 178 screened articles, 146 were excluded. This was predominately due to irrelevant content in respect to the objectives of this study. The remaining 47 studies were screened in full and three studies were removed. Thus, 44 studies were utilized for qualitative analysis.

\section{Findings and Discussion}

\subsection{Population Demographics}

Saudi Arabia is the second largest country in the Middle East. It is bordered by Jordan, Iraq, Kuwait, Qatar, 
Bahrain, the United Arab Emirates, Oman, and Yemen, and is adjacent to both the Red Sea and the Persian Gulf. In terms of total land mass, Australia is the sixth largest country in the world and encompasses Tasmania and a number of other pacific islands. Both Saudi Arabia and Australia are high functioning countries that draw substantial economic benefit from their respective export industries, and have well developed healthcare systems.

Saudi Arabia has a population of 31.1 million, whereas Australia has a population of approximately 24.4 million (Australian Bureau of Statistics [ABS], 2017; General Authority for Statistics, 2016). Saudi Arabia's General Authority for Statistics (2016) estimates approximately 10.2 million people in the Middle Eastern region to be immigrants, with the remaining 21 million people being Saudi Arabian. Australia is equally multicultural, with $15 \%$ of the population being immigrants from the United Kingdom, New Zealand, China, India, Philippines, Vietnam, Italy, South Africa, Malaysia, and Germany (ABS, 2016). Saudi Arabia and Australia have distinct population demographics: Saudi Arabia has a youthful population with a very high birth rate, and Australia has an ageing population with a significant portion of the working population transitioning into retirement (General Authority for Statistics, 2016; Kendig, McDonald, \& Piggott, 2016).

\subsection{Healthcare Organisation}

Public healthcare services are fully funded, supervised, and managed by the MOH in Saudi Arabia (Almalki, FitzGerald, \& Clark, 2011). In Australia, these services are managed by a combination of state and federal level governments (Australian Institute of Health and Welfare [AIHW], 2014). On a superficial level, this involves funding that is predominantly provided to the state government, after which spending is allocated. This demonstrates a disparity between the two systems: decentralisation in Australia and centralisation in Saudi Arabia. This phenomenon and the need to move towards increased levels of health management in the Saudi Arabian healthcare system will endeavour to augment the healthcare system in the future. The Saudi Arabian healthcare system offers less public services when compared to the Australian system. However, both Saudi Arabia and Australia have significantly established private health sectors (Almalki et al., 2011; Australian Institute of Health and Welfare [AIHW], 2014). This is reflected by the fact that approximately 55\% of Australians have private health insurance, while $40 \%$ of healthcare is privately funded in Saudi Arabia (Australian Bureau of Statistics [ABS], 2013; Ministry of Health [MOH], 2016). Due to systematic differences in the Saudi Arabian system, only a small proportion of the population is insured, a large number of whom are expatriates (Jannadi, Alshammari, Khan, \& Hussain, 2008). That being said, the KSA is beginning to move towards a stronger private healthcare sector.

\subsection{Healthcare Financing}

The Australian healthcare system costs approximately 9.5\% of Australia's total gross domestic product (GDP), which represents roughly $\$ 140$ billion AUD (AIHW, 2014). In contrast, Saudi Arabia allocates 4.7\% of their GDP to healthcare, representing (WHO, 2016b). In terms of the international dollar, Australia spends $\$ 4,357$ per capita on healthcare, and Saudi Arabia spends \$2,466 (WHO, 2016a). This demonstrates a startling difference in healthcare resource allocation, as Australia contributes almost \$2,000 more per capita than Saudi Arabia.

Funding for public healthcare in Australia is derived from global budgets and case-based payments (approximately $67 \%$ of national beds), and private healthcare is funded through insurance fee-for-service payments (approximately 33\% of national beds) (Mossialos, Wenz, Osborn, \& Anderson, 2015). The funding models of the healthcare system are complex, with hospitals having income from both private and public sources (AIHW, 2014). Figure 2 illustrates how services within hospitals are largely government funded and have minimal private share funding. In contrast, private hospitals are largely privately funded, with some federal and very limited state government funding (AIHW, 2014). Roughly 70\% of funding reserved for healthcare services in Australia comes from income tax, while 30\% comes from private stakeholders and insurance providers (AIHW, 2014). The majority of this funding $(67 \%)$ is allocated to private health services such as primary care clinics, specialist clinics, and laboratories, and 33\% is allocated to tertiary public hospitals (AIHW, 2014). 


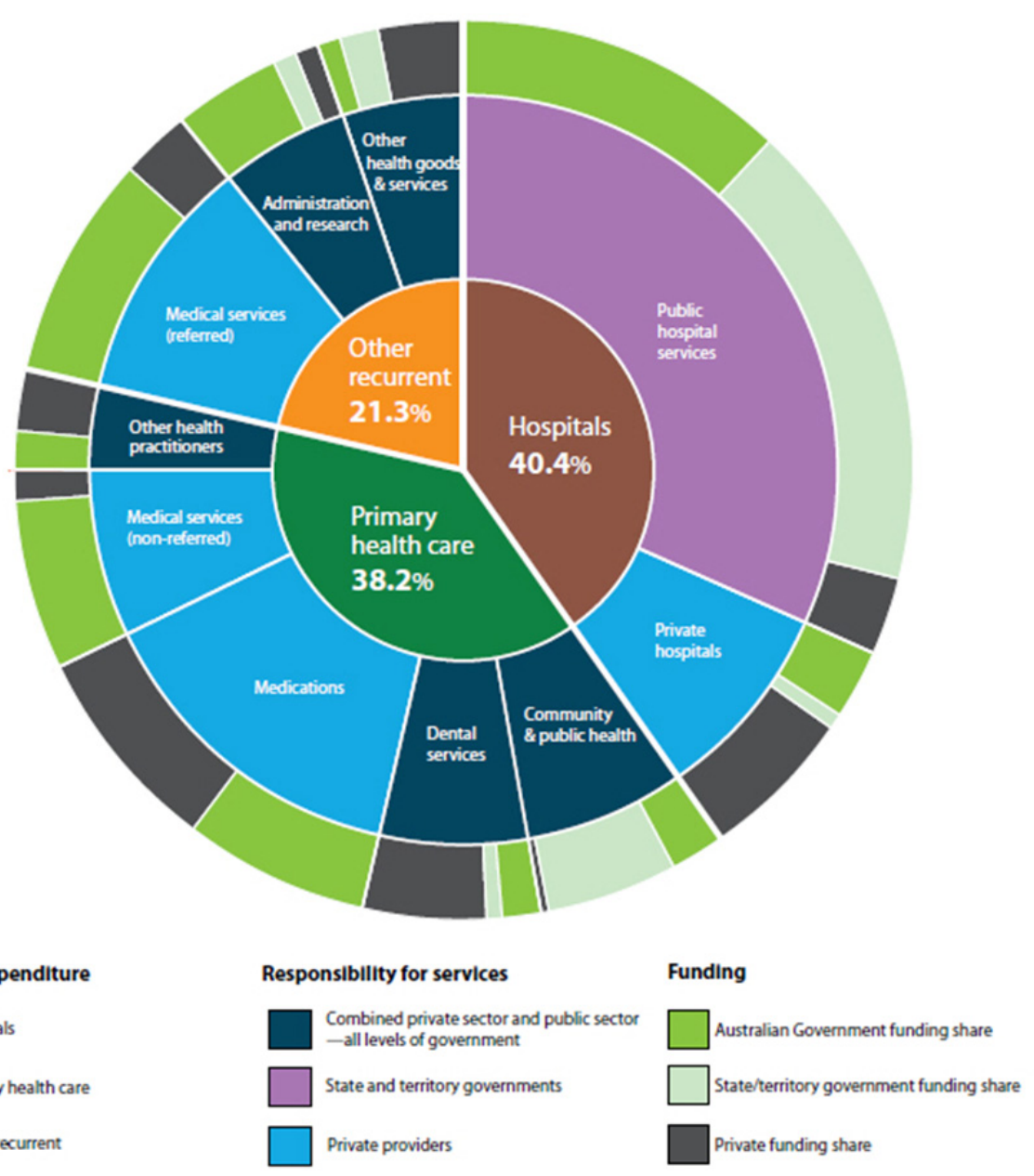

Figure 2. Funding and responsibilities of health services in Australia. Adapted from "Australia's Health System" by the Australian Institute of Health and Welfare [AIHW] (2014). Retrieved from http://www.aihw.gov.au/australias-health/2014/health-system/\#t3

The KSA operates under an entirely different funding paradigm. Private hospitals are financed by charging service fees, and public services are funded for the use of specific populations such as employees or military personnel (Figure 3) (Almalki et al., 2011). Approximately 20\% of public funding is allocated to specific ministerial departments in order the service specific populations. These departments include the Ministry of Defence, the Ministry of Education, the Ministry of the Interior, and the Ministry of the National Guard (A. A. Alkhamis, 2017). The funding of public hospital beds occurs through the $\mathrm{MOH}$, and accounts for $60 \%$ of the KSA's total healthcare budget (MOH, 2016). In comparison, $21.2 \%$ of all healthcare services occur in Australia's private sector across either primary, secondary or tertiary care levels. 


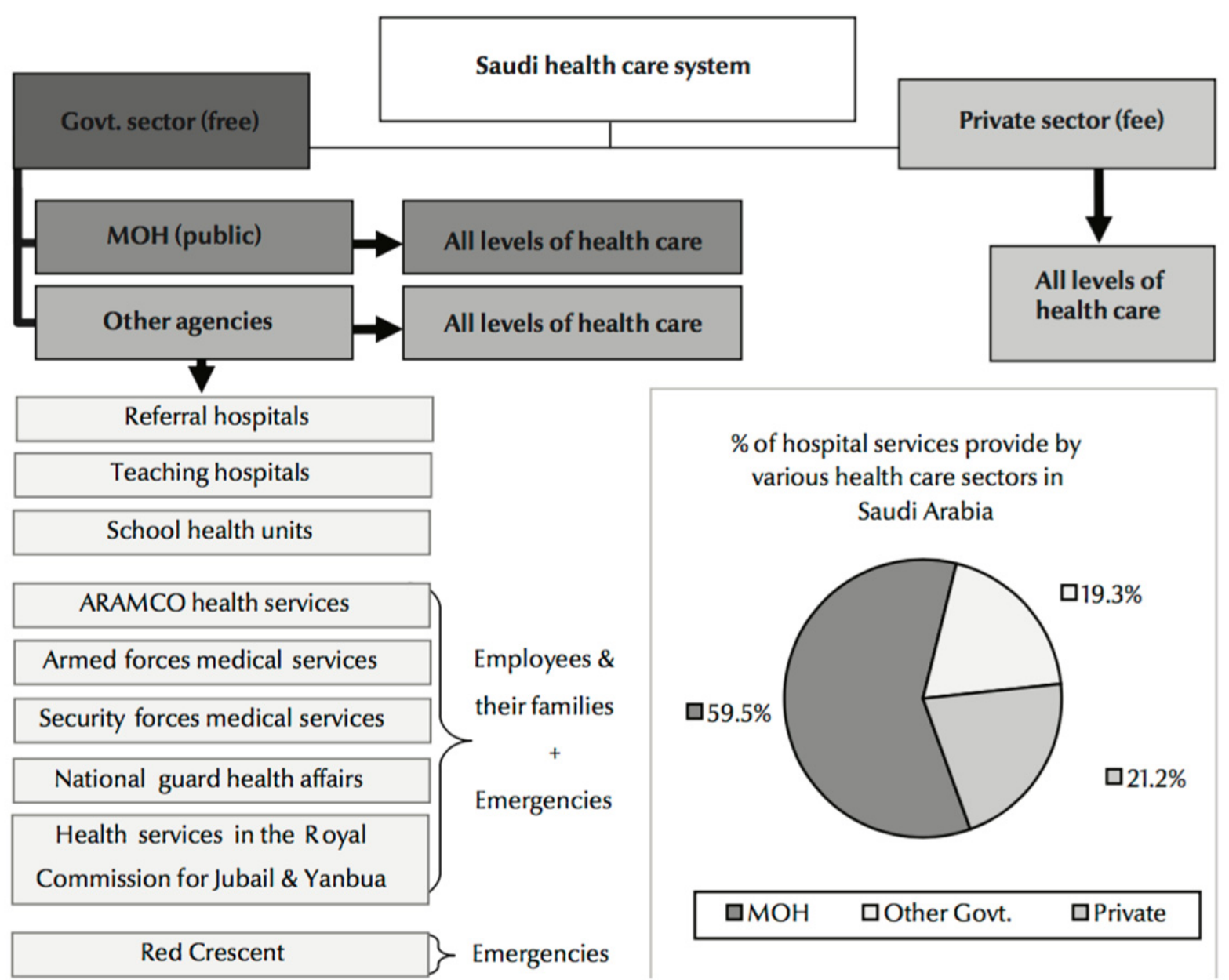

Figure 3. Current structure and funding of health services in Saudi Arabia. Adapted from "Health care system in Saudi Arabia: an overview" by Almalki et al. (2011). Eastern Mediterranean health journal, 17(10), 784

Funding methods differ between Australia and Saudi Arabia. All health service funding in Australia is activity-based funding (ABF), which requires vigorous patient reporting systems (Yesilada \& Direktor, 2010). In Saudi Arabia, the Ministry of Finances gives the $\mathrm{MOH}$ a significant budget, which is then utilised to fund public health services (Albejaidi, 2010). This centralised model does not allow for effective service planning and quality management when proactively adjusting to regional requirements on a needs basis (Albejaidi, 2010). Thus, a stronger funding framework based on the actual health needs of the population is required, as opposed to funding based upon retrospective budget review.

Australia's universal healthcare insurance system, Medicare, allows all Australians to access prioritised health services. The country also has a significant number of privately funded services. Together, approximately $67 \%$ of hospital beds are publically funded and 33\% are privately funded (Mossialos et al., 2015). Saudi Arabia also offers universal healthcare to its citizens and expatriates working in the public sector (Aldossary, While, \& Barriball, 2008; Jannadi et al., 2008). The Ministry of Health [MOH] (2016) provides funding for $59.5 \%$ of the hospital beds, and $40.5 \%$ are privately in the Kingdom.

Within the KSA, the $\mathrm{MOH}$ is responsible for creating healthcare policies, and for the planning, management, supervision, and evaluation of health outcomes (Al-Yousuf, Akerele, \& Al-Mazrou, 2002). In Australia, these functions are managed by a number of state and federal government (AIHW, 2014). The KSA may benefit from incorporating increased levels of regional management as it has been implemented within the Australian healthcare system. Doing so in combination with an increased number of private and partially funded services, healthcare costs may be managed more efficiently in the future.

\subsection{Healthcare Delivery}

For most people in Australia, a general practitioner (GP) will be their first encounter with the healthcare system 
(AIHW, 2014). The vast majority of GP clinics in Australia are privately owned. However, they are largely funded publically through individual Medicare rebate claims (AIHW, 2014). In Saudi Arabia, the MOH operates under primary, secondary, and tertiary levels of care. Similarly, primary care centres (equivalent to Australian GPs) act as the gatekeepers to more economically exhaustive tertiary levels of healthcare services (Almalki et al., 2011). The progressive decrease in tertiary health service engagement does correlate with increasing primary health clinics in Saudi Arabia to some degree (Al-Yousuf et al., 2002). However, there are a plethora of non-urgent presentations to emergency departments (ED) within the KSA (Alghanim \& Alomar, 2015). This indicates a need for the development of an increased primary care infrastructure, illustrating a degree of inaccessibility to primary care (Figure 4). Vision 2030 outlines the desire for the KSA to improve access to primary care as the first point of contact with the health system (Kingdom of Saudi Arabia [KSA], 2017). Primary health is an important element of accessibility. However, it is one of the few aspects of Vision 2030 that targets an improvement in accessibility. Despite this, the privatisation of more healthcare services is unlikely to facilitate the realisation of this objective.

\subsection{Theory and Driving Forces Behind Healthcare Privatisation}

The privatisation of healthcare is a liberal approach that involves aspects of free agency, public choice, and property rights, all of which emphasise privatisation as a means of augmenting performance and fiscal efficiency when compared to the public sector (A. A. Alkhamis, 2017). This is because incentives, objectives, and governance measures differ between the public and private sectors (A. A. Alkhamis, 2017; Preker, Harding, \& Travis, 2000). Accordingly, the aims of privatising health services in the KSA include alleviating the country's budget and increasing revenue, promoting competition, providing effectiveness and transparency, promoting local and foreign investment, broadening engagement in the production of new sectors, and creating employment opportunities while improving quality and decreasing service costs (Barrage, Perillieux, \& Shediac, 2007).

A labour-orientated perspective would argue that for-profit institutions take a surplus that should be given to community health service provisions (Carrigan, 2013). However, this depends on the model of privatisation. It is therefore critical to determine what privatisation truly means. In Australia, the healthcare system is predominately publically run and funded, with some privately owned institutions being partially publically funded. There are also some institutions that are completely private and elective. The standard of care is generally high, and while there may be psychological association with private care and enhance health outcomes, there is no evidence to suggest a distinction between private and public care systems (Van Doorslaer et al., 2008).

\subsection{Economic, Productivity, and Health Outcomes of Privatised Health Services}

It is important to consider the reasons behind the privatisation of healthcare services in developed and developing nations (A. Alkhamis, Hassan, \& Cosgrove, 2014; A. A. Alkhamis, 2017; Shah, 2009; Wang, Switlick, Ortiz, Connor, \& Zurita, 2010). Moreover, it is critical to recognise that Saudi Arabia has characteristics of both a developed and developing nation (A. Alkhamis et al., 2014). Australia, on the other hand, is undoubtedly a developed nation. This is significant, as the World Bank has influenced the drive for privatisation in developing nations (A. Alkhamis et al., 2014). Nonetheless, the KSA has maintained a universal health system. From a healthcare perspective, this suggests that the KSA to be a developed nation.

Following the global financial crisis, many countries opted to privatise certain aspects of their healthcare systems (A. A. Alkhamis, 2017; Herwartz \& Strumann, 2014). Bambra, Garthwaite, and Hunter (2014) state that many high-income countries experienced a change to accommodate extensive market-driven health systems and financial reform. Thus, the decision to privatise healthcare services protects governments from destabilisation in the event of a recession. Nonetheless, this decision is based on economics, and disregards aspects of public health such as equity, accessibility, healthcare, quality, and health outcomes. The KSA has publicly outlined its desire to privatise more health services in the aim of increasing efficiency and productivity. However, while the KSA is one of the only Arab nations to consider health equity as a goal, it fails to deliver public health and social policies (Karlsson et al., 2015). It can be argued that the robust public health system in Australia has led the country to be one of the healthiest in the world. However, the private sector has helped to provide aspects of care, and in particular tertiary level intervention, not required by public hospitals. This has left the use of public hospitals for acute situations and health management among those unable to afford private insurance.

Significant evidence contradicting one or more of the fundamental rationales for privatising healthcare services exists within both Australian and international literature (Basu, Andrews, Kishore, Panjabi, \& Stuckler, 2012; Tiemann \& Schreyögg, 2012; Tracy et al., 2014). A German study evaluating changes in efficiency upon converting from public to private for-profit healthcare status found that a private status correlated with a $2.9-4.9 \%$ increase in efficiency (Tiemann \& Schreyögg, 2012). Interestingly, a study by Auerbach and Kellermann (2011)found that while privatisation may present the opportunity for productivity gain, it is offset by the rising cost 
of free-market fee increases that outstrip wage growth. Moreover, considering the impact of privatisation on performance in line with WHO criteria (accessibility and responsiveness, quality of care, health outcomes, accountability, transparency and regulation, fairness and equity, and efficiency), Basu et al. (2012) found that private care is no more productive, accountable, or clinically effective than public care. This outcome aligns with several other studies in various populations (Berendes, Heywood, Oliver, \& Garner, 2011; Kondilis et al., 2011; Yesilada \& Direktor, 2010). Waitzkin, Jasso-Aguilar, and Iriart (2007)highlight that the privatisation of the health care system amplifies administrative costs. Therefore, one question remains: does the privatisation of healthcare services provide true economic and productivity gains when offset by higher administrative costs, lower accountability and transparency, and rising fees due to free-market forces?

\subsection{What It Means to Have Accessible Health Services}

Accessibility can be defined many ways. For instance, a country with a universal healthcare system can be considered inaccessible if there is an imbalance between need and service provisions. As such, Australia has accessibility issues due to the distance between major cities and the lack of services available in rural and remote locations. However, the system does an overall satisfactory job of ensuring needs-based care and horizontal equity (Van Doorslaer et al., 2008). The KSA faces a similar challenge due to its environment, with many services located within major cities and minimal services available to support rural and remote communities (Almalki et al., 2011). While Australia has a strong and stable the healthcare workforce, the KSA has a low physician and nurse to patient ratio, which is largely made up of expatriates. This creates instability within the workforce (Almalki et al., 2011).

In countries that have universal health systems, including Australia and Saudi Arabia, all citizens who are unwell have free access to medical care. This care is prioritised based upon need. For example, a life-threatening illness or injury will be managed prior to a minor illness or injury. This model satisfies one of the four major criteria required in providing accessible healthcare services (Figure 4). However, accessibility also depends upon other factors, namely that the system is sustainably funded, used rationally to promote efficiency, and is reliable in terms of health service delivery and supply systems.

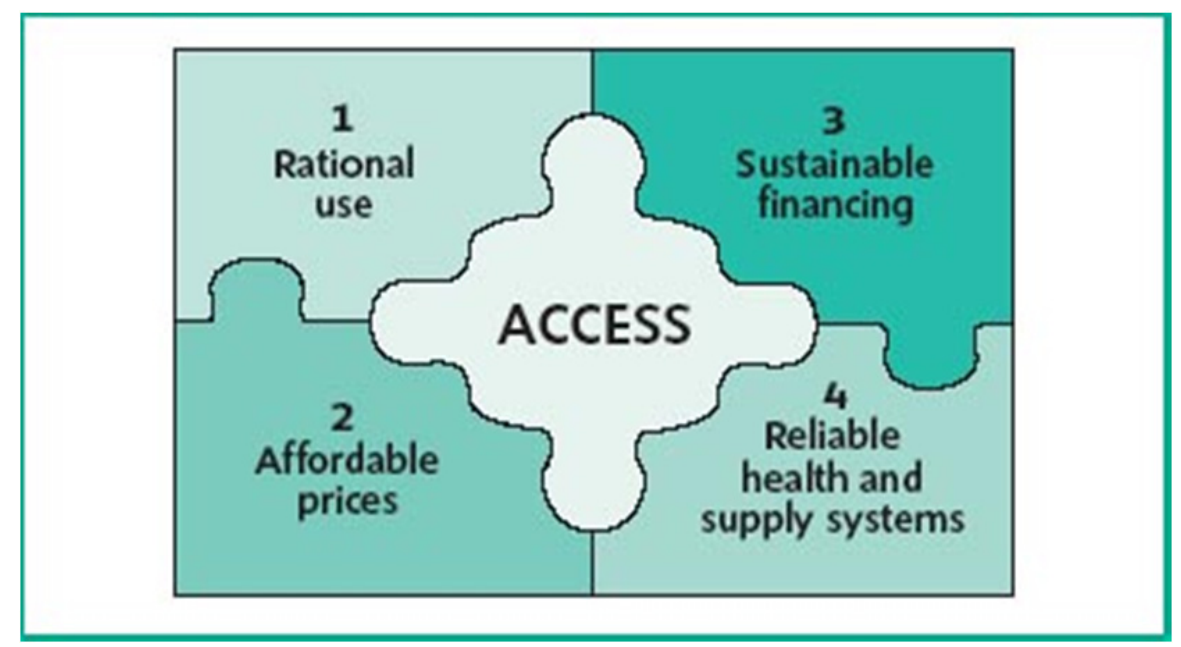

Figure 4 . How accessibility to healthcare is achieved

\subsection{Impact of Privatisation and Funding Models on Accessibility to Health Services}

Health outcomes largely depend on the state of the implemented healthcare system (Xu, Saksena, \& Evans, 2010). However, in order for a well-developed healthcare system to be beneficial to the public, it must be widely accessible (Xu et al., 2010). Direct access to preventative and curative services, along with the prevention of financial hardship when seeking services are two essential components of universal accessibility (WHO, 2005). The latter is a major concern of service privatisation. This is because while costs are driven down in theory, privatisation creates a free-market wherein healthcare providers can charge according to their desire without using a predetermined schedule. For example, the United States of America has a highly privatised system, yet it spends the most of any country globally on healthcare (Mossialos et al., 2015). Thus, privatisation does not directly correlate with decreasing healthcare funding requirements and efficiency. It may also hinder accessibility, contrary to reports praising privatisation as the ultimate healthcare solution. A decrease in financial accessibility fails one of 
the four criteria of accessible services: affordable prices. The shift to a more privatised system in Saudi Arabia will likely increase out-of-pocket costs, moving the country away from providing equitable accessibility to healthcare services. Moreover, privatisation will allow large corporations to focus on urban hospitals, further disadvantaging smaller rural and remote communities (Almalki et al., 2011). While not directly an aspect of accessibility, this speaks to both the financial sustainability of the proposed plan and the reliability of the system.

A simple relationship exists when considering the KSA's plan to privatise state healthcare services: the level of healthcare privatisation and funding methods will ultimately determine the level of healthcare accessibility and the public health outcomes the system can achieve. Moreover, accessibility in Saudi Arabia will depend on its ability to maintain universal healthcare for those unable to pay for private health insurance. Because public hospitals are the safety net of those unable to afford private health services, they are subject to an increase in complex presentations due to poorer health outcomes among lower socioeconomic groups. Thus, public hospitals are subject to an increase in financial stress (Ramamonjiarivelo et al., 2015). Consequently, public hospitals may fold to privatisation, diminishing the strength of the safety net for lower socioeconomic groups. If this scenario were reversed, it is likely that the vulnerable populations would be the most affected. This decreases accessibility to appropriate care. Waitzkin et al. (2007) found that privatisation (either through the transformation of public services to private services or allowing corporate penetration for insurance provision and development of the private sector) has not yielded a significant increase in healthcare accessibility.

\section{Conclusion and Recommendations}

Privatisation of health services in the KSA appears to be a case of a wolf dressed in sheep's clothing. The KSA has failed to adequately address the ways in which its healthcare system will safeguard public health outcomes and indicators. This includes the probability of decreased accessibility and equity in the course of privatising hundreds of hospitals throughout the nation. The Australian healthcare example demonstrates an alternate option wherein private health insurance is incentivised, and the organic growth of private health institutions allows access to those who can afford elective and non-elective care. Under this model, the safety net of well-funded public services remains robust in order to protect those unable to pay for private healthcare services. As Alshamsan, Leslie, Majeed, and Kruk (2017) point out, Saudi Arabia requires policies that target the needs of disadvantaged, vulnerable, and less educated.

If the KSA is to transition to a model of private healthcare ownership, an extensive governance framework is needed in order to support its objectives. This must be done to avoid higher fees, administrative costs, and profit-seeking behaviours of healthcare providers. A discussion regarding the centralised model of service management is beyond the scope of this research. However, a centralised model is unlikely able to uphold managerial and governance activities in order to facilitate transition to an effective private health sector. Therefore, a decentralised model that delegates increased responsibility to regional directorates would be better suited in dealing with the proposed strategy.

Ultimately, this paper does not condemn the plan to integrate more private health services in the KSA; it simply illustrates the risks of health service accessibility and economic decline if not appropriately planned and managed. There is substantial evidence indicating that if the KSA implements the privatisation of its healthcare sector, healthcare and administrative costs will rise, and care provided will be no more effective than the current public healthcare system. Therefore, Vision 2030 does not properly consider the downsides of this proposal, or align the plan to the appropriate mitigation strategies, particularly when it comes to the core function of healthcare: delivering accessible and high quality health services to the population.

\section{Competing Interests Statement}

The authors declare that there are no competing or potential conflicts of interest.

\section{References}

Al-Yousuf, M., Akerele, T. M., \& Al-Mazrou, Y. Y. (2002). Organization of the Saudi health system. Eastern Mediterranean health journal $=$ La revue de sante de la Mediterranee orientale $=$ al-Majallah al-sihhiyah li-sharq al-mutawassit, 8(4-5), 645. https://doi.org/10.1016/j.jplph.2004.06.005

Albejaidi, F. M. (2010). Healthcare System in Saudi Arabia: An Analysis of Structure, Total Quality Management and Future Challenges. Journal of Alternative Perspectives in the Social Sciences, 22(22), 794-818. Retrieved from http://fac.ksu.edu.sa/sites/default/files/mqlh_n_lnzm_lshy_lswdy-njlyzy.pdf

Aldossary, A., While, A., \& Barriball, L. (2008). Health care and nursing in Saudi Arabia. International nursing review, 55(1), 125-128. 
Alghanim, S. A., \& Alomar, B. A. (2015). Frequent use of emergency departments in Saudi public hospitals: implications for primary health care services. Asia Pacific Journal of Public Health, 27(2), NP2521-NP2530.

Alkhamis, A., Hassan, A., \& Cosgrove, P. (2014). Financing healthcare in Gulf Cooperation Council countries: a focus on Saudi Arabia. The International journal of health planning and management, 29(1)

Alkhamis, A. A. (2017). Critical analysis and review of the literature on healthcare privatization and its association with access to medical care in Saudi Arabia. Journal of infection and public health, 10(3), 258-268.

Almalki, M., FitzGerald, G., \& Clark, M. (2011). Health care system in Saudi Arabia: an overview/Aperçu du système de santé en Arabie saoudite. Eastern Mediterranean health journal, 17(10), 784.

Alshamsan, R., Leslie, H., Majeed, A., \& Kruk, M. (2017). Financial hardship on the path to universal health coverage in the Gulf states. Health Policy, 121(3), 315-320.

Auerbach, D. I., \& Kellermann, A. L. (2011). A decade of health care cost growth has wiped out real income gains for an average US family. Health Affairs, 30(9), 1630-1636.

Australian Bureau of Statistics [ABS]. (2013). Australian Health Survey: Health Service Usage and Health Related Actions, 2011-12. Retrieved from http://www.abs.gov.au/ausstats/abs@.nsf/lookup/E334D0A98272E4DCCA257B39000F2DCF?opendocume nt

Australian Bureau of Statistics [ABS]. (2016). Migration, Australia, , 2014-15. Retrieved from http://www.abs.gov.au/ausstats/abs@.nsf/0/66CDB63F615CF0A2CA257C4400190026?Opendocument

Australian Bureau of Statistics [ABS]. (2017). Population Clock. Retrieved from http://www.abs.gov.au/ausstats/abs@.nsf/Web+Pages/Population+Clock?opendocument

Australian Institute of Health and Welfare [AIHW]. (2014). Australia's Health System. Retrieved from http://www.aihw.gov.au/australias-health/2014/health-system/\#t3

Bambra, C., Garthwaite, K., \& Hunter, D. (2014). All Things Being Equal: Does it Matter for Equity How You Organize and Pay for Health Care? A Review of the International Evidence. International Journal of Health Services, 44(3), 457-477. https://doi.org/10.2190/HS.44.3.c

Barrage, G., Perillieux, R., \& Shediac, R. (2007). Investing in the Saudi Arabian Healthcare

Sector. Retrieved from http://www.booz.com/media/file/Investing_in_the_Saudi_Arabian_Healthcare_Sector_ FINAL.pdf

Basu, S., Andrews, J., Kishore, S., Panjabi, R., \& Stuckler, D. (2012). Comparative performance of private and public healthcare systems in low-and middle-income countries: a systematic review. PLoS medicine, 9(6), e1001244.

Berendes, S., Heywood, P., Oliver, S., \& Garner, P. (2011). Quality of private and public ambulatory health care in low and middle income countries: systematic review of comparative studies. PLoS medicine, 8(4), e1000433.

Carrigan, C. (2013). Privatisation: the threat to Australia's public hospitals. Australian Nursing and Midwifery Journal, 21(3), 28.

General Authority for Statistics. (2016). Population by Gender, Age groups and Nationality (Saudi/non-Saudi). Retrieved from http://www.cdsi.gov.sa/en/4068

Herwartz, H., \& Strumann, C. (2014). Hospital efficiency under prospective reimbursement schemes: an empirical assessment for the case of Germany. The European Journal of Health Economics, 15(2), 175-186.

Jannadi, B., Alshammari, H., Khan, A., \& Hussain, R. (2008). Current structure and future challenges for the healthcare system in Saudi Arabia. Asia Pacific Journal of Health Management, 3(1), 43.

Karlsson, L. E., Saleh, F., Azam, S., Larsen, E. L., Andersen, P. T., \& AL-Rammah, T. Y. (2015). How are health equity aspects articulated in the public health policy documents in Saudi Arabia. Paper presented at the EUPHA Conference in Milan, 14-17 October, 2015, Milan, Italy

Kendig, H., McDonald, P., \& Piggott, J. (2016). Population Ageing and Australia's Future.

Kingdom of Saudi Arabia [KSA]. (2017). Vision 2030. Retrieved from http://vision2030.gov.sa/en/node/9

Kondilis, E., Gavana, M., Giannakopoulos, S., Smyrnakis, E., Dombros, N., \& Benos, A. (2011). Payments and quality of care in private for-profit and public hospitals in Greece. BMC health services research, 11(1), 234. 
Ministry of Health [MOH]. (2016). Statistical yearbook 1436. Retrieved from http://www.moh.gov.sa/en/Ministry/Statistics/book/Documents/StatisticalBook-1436.pdf

Moher, D., Liberati, A., Tetzlaff, J., \& Altman, D. G. (2009). Preferred reporting items for systematic reviews and meta-analyses: the PRISMA statement. Annals of internal medicine, 151(4), 264. https://doi.org/10.7326/0003-4819-151-4-200908180-00135

Mossialos, E., Wenz, M., Osborn, R., \& Anderson, C. (2015). 2014 International Profiles Of Health Care Systems. Retrieved from http://www.commonwealthfund.org/ /media/files/publications/fund-report/ 2015/jan/1802_mossialos_intl_profiles_2014_v7.pdf

Preker, A. S., Harding, A., \& Travis, P. (2000). Make or buy" decisions in the production of health care goods and services: new insights from institutional economics and organizational theory. Bulletin of the World Health Organization, 78(6), 779-790.

Ramamonjiarivelo, Z., Weech-Maldonado, R., Hearld, L., Menachemi, N., Epané, J. P., \& O'Connor, S. (2015). Public hospitals in financial distress: Is privatization a strategic choice? Health care management review, 40(4), 337-347.

Shah, N. M. (2009). The management of irregular migration and its consequence for development: Gulf Cooperation Council.

Tiemann, O., \& Schreyögg, J. (2012). Changes in hospital efficiency after privatization. Health Care Management Science, 15(4), 310-326.

Tracy, S., Welsh, A., Hall, B., Hartz, D., Lainchbury, A., Bisits, A., . . . Tracy, M. (2014). Caseload midwifery compared to standard or private obstetric care for first time mothers in a public teaching hospital in Australia: a cross sectional study of cost and birth outcomes. BMC Pregnancy and Childbirth, 14(46), 46. https://doi.org/10.1186/1471-2393-14-46

Van Doorslaer, E., Clarke, P., Savage, E., \& Hall, J. (2008). Horizontal inequities in Australia's mixed public/private health care system. Health policy, 86(1), 97-108. https://doi.org/10.1016/j.healthpol.2007.09.018

Waitzkin, H., Jasso-Aguilar, R., \& Iriart, C. (2007). Privatization of Health Services in Less Developed Countries: An Empirical Response to the Proposals of the World Bank and Wharton School. International Journal of Health Services, 37(2), 205-227. https://doi.org/10.2190/A1U4-7612-5052-6053

Wang, H., Switlick, K., Ortiz, C., Connor, C., \& Zurita, B. (2010). Health Insurance Handbook: How To Make it Work: Health Systems 20/20 project, Abt Associates In: Bethesda.

World Health Organisation [WHO]. (2005). Sustainable health financing, universal coverage and social health insurance. Retrieved from http://apps.who.int/medicinedocs/documents/s21475en/s21475en.pdf

World Health Organisation [WHO]. (2016a). Australia Retrieved from http:/gamapserver.who.int/gho/interactive_charts/mbd/life_expectancy/atlas.html

World Health Organisation [WHO]. (2016b). Saudi Arabia. Retrieved from http://www.who.int/countries/sau/en/

Xu, K., Saksena, P., \& Evans, D. B. (2010). Health financing and access to effective interventions. World Health Report (2010) Background Paper, 8

Yesilada, F., \& Direktor, E. (2010). Health care service quality: A comparison of public and private hospitals. Afr. J. Bus. Manag., 4(6), 962-971.

\section{Copyrights}

Copyright for this article is retained by the author(s), with first publication rights granted to the journal.

This is an open-access article distributed under the terms and conditions of the Creative Commons Attribution license (http://creativecommons.org/licenses/by/4.0/). 